\title{
Identidad(es) literaria(s): el exilio en las poetas hispanomexicanas
}

\section{Identity(s) literary(s): the exile in the hispanic-mexican poets}

\author{
Katia Irina Ibarra Guerrero \\ Mariana Masera \\ Universidad Nacional Autónoma de México, México
}

\begin{abstract}
Resumen: Entre los poetas de la segunda generación del exilio republicano español en México, se muestran algunas voces femeninas que representan una particular identidad literaria. Sin ser propiamente un grupo, poetas como Nuria Parés, Angelina Muñiz y Francisca Perujo expresan una concepción del exilio, de la memoria y lo femenino como parte de su propuesta poética. Aquí se hace un esbozo de algunos de sus poemas en el contexto de los estudios sobre el exilio literario.

Palabras clave: Poesía Hispanomexicana, poesía del exilio, mujeres poetas, poesía mexicana contemporánea.
\end{abstract}

Abstract: Among the poets of the second generation of Spanish Republican exile in Mexico, some female voices representing a particular literary identity are presented. Without being properly a group, poets like Nuria Pares, Francisca Perujo and Angelina Muñiz express a conception of exile, memory and feminine as part of their poetic proposal. Here is an outline of some of their poems in the context of studies on the literary exile.

Keywords: Hispanic-mexican poetry, Exile’s poetry, Women's poetry, Contemporary mexican poetry.

Recibido: 08 de septiembre 2016

Aceptado: 12 de abril de 2017 
Pensar que a tantos años de distancia, pasadas tantas cosas en el mundo y en nuestras vidas, esa guerra esté todavia en el fondo de nuestra memoria es algo que puede extrañar a una mente objetiva que nos contemple desde lejos.

Arturo Souto

\section{(...) mi patria es el mar}

pero tampoco pertenezco (...).

Angelina Muñiz-Huberman

Cómo abordar la poesía sobre exilio? ¿De qué forma el exilio se convierte en el material para la producción poética? En este artículo nos remitimos a la segunda generación del exilio republicano en México, también llamada el grupo hispanomexicano (Souto, Mateo Gambarte, Sicot, Rivera, entre otros). Partimos de que el exilio es primero una "vivencia" y después se convierte en un relato, en una forma de vivir el tiempo y construir la memoria. En el caso del exilio español republicano, esta memoria, este traer al presente la vivencia de la partida, se mezcla con el sentimiento de la derrota, la expulsión, el dolor por lo dejado, el horror de la guerra. El exilio ${ }^{1}$ es también un territorio, una forma de definición, un tiempo y espacio, un incierto asidero. Con estos supuestos, creemos que una forma para aproximarse a los textos poéticos del exilio es partiendo del planteamiento de la construcción de la identidad. Este pilar de la modernidad, que conlleva a cuestiones culturales, ontológicas, entre otras, al presentarse en la poesía y la

${ }^{1}$ Término exilio, más general y amplio, más contemporáneo, que se refiere a la partida de una persona de su lugar de origen, por diversas causas pero en este caso por cuestiones políticas, y también como el lugar a donde se parte. Lo empleamos en un sentido abarcador de otros términos más precisos e históricos como lo es el transtierro de Gaos, o el destierro de Sánchez Vázquez. 
literatura, resulta un aspecto por demás complejo pero sumamente interesante para la interpretación literaria. La identidad poética puede plantearse, entonces, como el pretexto para acercarse a la obra de las mujeres poetas de la segunda generación de este exilio. Hijas de refugiados, vivieron esta experiencia desde otro ángulo, pues apenas eran niñas o adolescentes; mediante el artificio poético (complejo y lleno de incertidumbres), reconstruyen los relatos sobre el exilio que sus padres les narraban; asimilaron esta condición y la convirtieron en el eje de algunos de sus poemas. Menos conocidas que otros poetas de su generación, autoras como Nuria Parés, Angelina Muñiz-Huberman y Francisca Perujo conforman parte de esta generación literaria de una forma particular.

\section{Poética del exilio}

Hay ideas que obsesionan y se convierten en el tema central de la escritura. Para los escritores que partieron de su lugar de origen, en el contexto de la Guerra Civil Española y la derrota de la República, el exilio se volverá obsesión y se manifestará en diversas maneras. Para los escritores, poetas e intelectuales involucrados en estos acontecimientos, el tema del exilio (aunque es más que un tema, es una condición, una identidad...) se muestra en diferentes formas: en el ensayo se abordará la forma particular que tiene el pensamiento español a diferencia del europeo del norte -así sucede con María Zambrano y su obra Filosofía y poesía, publicado justo el año de los primeros arribos de los exiliados a México- o bien el insistente abordaje de la cultura española en muchos ensayistas exiliados; en la narrativa, se expresa en el tema de los viajes, la identidad, el ideal del retorno, retomando la tradición hispánica; en la poesía, preponderan las imágenes marítimas, el motivo de Ítaca, el sentimiento de desarraigo, incluso de orfandad. Todo ello desemboca en un mismo punto: la obsesión por el exilio y la manera en 
que éste marca la identidad literaria; es decir, en los intereses más profundos y personales de los autores.

Son muchos los estudiosos de la literatura e investigadores que han abordado el tema del exilio directa o tangencialmente; asimismo, en años recientes, ha habido cada vez un mayor interés por estudiar el exilio republicano en México desde el enfoque de la literatura. Ejemplo de ello son los estudios de Eduardo Mateo Gambarte y de Bernardo Sicot, ${ }^{2}$ que han ahondado en este acontecimiento de una forma más académica y han penetrado en temas muy específicos como lo es la forma en que el exilio está presente en la poesía. Por otra parte, la obra de Angelina MuñizHuberman, hija de exiliados, llegada a México cuando era niña, es también un caso paradigmático de esta atención al tema y su vinculación con la literatura. Muñiz en su obra, El canto del peregrino (1999), va más allá al proponer una poética del exilio. Con esta mira, plantea en primer lugar ver en términos amplios lo que implica esta condición de "ser separado de la tierra donde se vive", lo que lleva a trazar un exilio mítico-histórico. Así, desde la tradición judeo-cristiana tenemos que el primer exilio es la expulsión del paraíso. Es el saberse expulsado, con la pérdida que esto conlleva, con la memoria y la nostalgia por lo perdido y, sobre todo, la añoranza-deseo por el regreso, es lo que se desprende de este motivo bíblico. El influjo de la cultura judía, ${ }^{3}$ lleva a Muñiz a entablar

${ }^{2}$ Del primero, su obra resulta un significativo aporte a la relectura del exilio republicano en México y particularmente de la segunda generación, entre sus títulos está el aquí citado: Literatura de los "niños de la guerra" del exilio español en México (1996); el segundo, ha dedicado diversos estudios y publicado libros sobre el exilio español entre los cuales se encuentran "El mar de los desterrados. Desde Unamuno hasta los poetas hispanoamericanos" y la antología Ecos del exilio: 13 poetas del exilio. 3 "[...] el exilio forma parte del proceso de la creación, lo que constituye la originalidad del pensamiento cabalista. Si el exilio sobrepasa la idea de 
varios aspectos de lo que es el exilio y la manera en que se hace presente, primero en la construcción de la identidad, y luego en la estructura profunda de los textos literarios. Para Angelina, desde su pensamiento vinculado a esta tradición, el exilio es una forma de destino, pero también es redención.

El exilio es forma histórica vigente desde la antigüedad hasta nuestros días. El exilio es forma literaria, es forma imaginada y es forma de la memoria. Es evidente que parte de una realidad, pero de inmediato corta su relación con lo real y pasa a ser asunto de ficción. La única manera de sobrevivir para el exiliado es haciendo uso y práctica de los procesos mentales internos (Muñiz, 1999: 65).

$\mathrm{Al}$ abordar el tema de la lengua y su relación con el exilio, Angelina Muñiz sitúa la manifestación del lenguaje (tema que también estará presente en otros de los exiliados de la "segunda generación", como Segovia y Xirau, y es estudiado por Mateo Gambarte y Sicot) en el centro de esta poética.

La experiencia del exilio se refleja en el lenguaje, desde épocas antiguas hasta nuestros días y esto nos lleva hacia la creación de una poética. El idioma propio, entre los otros idiomas de las tierras extrañas, sufre, de igual modo, desplazamiento y se preserva en formas de una lenta evolución o de una reservada idealización. Esto fue lo que ocurrió con el idioma español (ladino) que llevaron consigo al exilio los judíos sefardíes. Circunstancia idéntica

ser una prueba o un castigo, se convierte, entonces, en una misión que cumplir. El propósito de esta misión es liberar el alma humana de sus ataduras terrenas, elevarla a la luz divina e integrarla en el todo cósmico. Abarca, además, la idea de redención, pues el pueblo desterrado y lanzado en todas direcciones aspira al perfeccionamiento del alma entre cada uno de los seres [...]" (Muñiz, 1999: 78). 
con cualquier exilio moderno. El lenguaje pasa a ser, entonces, la esencia del Universo, como lo había sido en el Génesis por su calidad nominativa. Para los escritores de nuestro siglo será la esencia de su poética (Muñiz, 1999: 80).

Desde esta interpretación del exilio, Muñiz propone al lenguaje como la casa del exiliado y la vía por la cual se apropia de esta "condición”. Es la forma de aprehender el acontecimiento, el tiempo mismo, como diría Ricoeur -en su obra Tiempo y narración-, y por lo tanto es mediante el lenguaje que se construye la identidad del exiliado, la memoria misma que es el origen de dicha identidad. La poesía resulta entonces la vía idónea para poner en manifiesto esta condición identitaria. Pero no es sólo la poesía, sino que la unión de esta manifestación pura del lenguaje con la modernidad da como resultado esa poética del exilio. De ahí que retomemos de su "Decálogo del exilio" (El canto peregrino) dos aspectos fundamentales: la idea de la modernidad, como "lugar" desde dónde puede plantearse propiamente esta poética, y la idea de la "invención", pues al final de todo, el exilio es una invención en tanto relato, ya que está el hecho histórico, pero, aún más importante es la forma en que el sujeto se apropia de ese acontecimiento, lo inventa discursivamente, lo reinventa a través de la escritura en ese complejo proceso que va de la memoria a la expresión literaria.

Es en la modernidad cuando podremos pensar que el exilio se dirige hacia la creación de una poética. En algunos autores será más consciente que en otros, en algunos más se diluirá, pero en todos los casos subyacerá de manera más o menos explícita $(\mathrm{Mu}-$ ñiz, 1999: 87).

Como el tiempo de Ricoeur, que sólo es tangible en tanto se narra mediante el lenguaje, el exilio sólo puede ser aprehendido, entendido, intuido, asimilado, etcétera, gracias al lenguaje. Lo que 
resulta es el exilio poético en el universo poético mismo, que no es más que una invención. La identidad no es más que la historia que nos contamos y en tanto que la contamos es que se torna "real". Así, dice Muñiz, a propósito del poeta exiliado Joseph Brodsky: "Lo que nos dice Brodsky es que la verdadera y única experiencia es la poética: que ésta modela a la experiencia real y que, por lo tanto, el exilio no es sino una invención” (Muñiz, 1999: 92).

\section{El exilio republicano en México}

Hablando del exilio propiamente histórico que devino de la Guerra Civil espańola, la llegada de los refugiados republicanos a México trajo grandes aportaciones a la cultura de este país. Por esto, su estudio es crucial para entender buena parte del siglo XX. José María Espinasa, por ejemplo, en su trabajo introductorio a la edición digital de la revista Presencia ${ }^{4}$ aborda la importancia de este acontecimiento para la cultura mexicana, en los términos más amplios. Sin embargo, particularmente sobresale el contexto social, político e histórico del gobierno de Lázaro Cárdenas que posibilitó la recepción de los exiliados (e incluso de los niños de guerra que el propio Cárdenas traería, conocidos como los niños de Morelia). Este es el punto de partida:

No hay que olvidar el contexto político, la Revolución Mexicana, que había alcanzado su mejor representación en el gobierno de Lázaro Cárdenas en los finales años treinta-momento en el que el régimen abre las puertas al exilio español después de un decidido, aunque tal vez poco significativo en términos militares, apoyo a

${ }^{4}$ Edición digital de la revista Presencia, en la que participaron varias figuras de esta segunda generación del exilio, realizada por el Ateneo Español de México y Ediciones Sin Nombre en 2015 y auspiciada por el Centro Cultural de Espańa en México, entre otras asociaciones. 
la República y a su legalidad y legitimidad democrática- [...]. Si bien el sistema político estaba todavía regido por el caudillismo, Cárdenas sentó las bases pragmáticas para la consolidación de un sistema de equilibrios que caracterizó al país en los siguientes cincuenta ańos (Espinasa, 2014: 17).

En el contexto de este exilio histórico, los artistas e intelectuales que llegaron a México reflexionaron sobre esta condición y propusieron términos para referirse a ella: desde el concepto de "refugiado", el cual fue aceptado por algunos -que implica la guerra en el lugar de origen de la persona refugiada-, o bien el de "aterrado" o "desterrado" -que implica la desposesión de la tierra, del país, el ser expulsados por cuestiones políticas-. Así, se propone otro término como el de "transterrado", acuñado por José Gaos (1994: 3-9). El transtierro, por una parte, lleva a una extrapolación de un lugar a otro y, por otra, lleva la palabra "tierra" como una forma en que se manifiesta el territorio como parte fundamental de la identidad. En efecto, el sentimiento principal de muchos de los transterrados será el de reproducir la España perdida, aún más la España republicana en tierras mexicanas, gracias a las conexiones culturales ya existentes. Asimismo, estará muy presente, en muchos de ellos, la idea del regreso, de la restauración de la República. De ahí que se aferraran y construyeran instituciones propias para la preservación de la ideología republicana y las costumbres españolas. Por esto, muchos transterrados, en sintonía con esta idea del retorno, inculcaron en sus hijos la idea de ser españoles. Las ideas o conceptos de "transterrado", "desterrado", "aterrado", "exiliado" han sido objeto de discusión intelectual, y aún hoy siguen siendo problemáticas. En este artículo, no se profundizará en este debate y se hablará del término de transtierro desde la concepción antes expuesta, y cómo este término es asimilado y representado en la poética de las autoras de la segunda generación del exilio aquí abordadas. 
Tenemos entonces la idea del "transtierro" como una idea surgida de la experiencia de estos intelectuales llegados a México. Dentro del transtierro encontramos la experiencia de los intelectuales mayores, así como de los más jóvenes a los que se les ha abordado bajo diversas categorías: segunda generación del exilio, hispanomexicanos, nueva generación, entre otros. Max Aub fue quien por primera vez se refirió a los más jóvenes como una generación particular, calificada como Nepantla (en medio de dos tierras), en su breve ensayo "Una nueva generación", publicado originalmente en enero de 1950 en los cuadernillos titulados Sala de espera: "Cogidos entre dos mundos, sin tierra firme bajo sus pies, influenciados por un movimiento filosófico irracionalista, con una Espańa de segunda mano, no acaban de abrir los ojos a la realidad" (Aub, 1987: 111).

En el terreno de la literatura, varios han estudiado el exilio español y su propuesta estética. Bernardo Sicot en su ensayo "El mar de los desterrados", se aproxima a los poetas que vivieron el exilio en su madurez intelectual y literaria, que fueron los "derrotados" por la dictadura, y que transmiten en su obra un sinfín de aspectos propios de este acontecimiento. Dice Sicot: "Como el desierto, como el camino, el mar es un motivo de la poesía del exilio, tal vez no suficientemente estudiado hasta ahora" (2006: 900). Lo que resulta interesante, además de los temas que apunta Sicot y que, en efecto, dan aún mucha materia para estudio, es ver cómo las obsesiones presentes en la literatura y el pensamiento de los exiliados se reproducen de una u otra manera en las poéticas de la siguiente generación, particularmente en textos de algunas escritoras y poetas como las abordadas en este artículo. Siguiendo el análisis hecho por Sicot, tenemos que hay una serie de imágenes y metáforas recurrentes en la primera y la segunda generación. Particularmente la imagen del mar y lo relacionado con él, como los barcos, los puertos, la playa: 
[el mar] cobra en el exilio, además de sus habituales valores de expresión de la libertad viajera, otros, polisémicos: es la verdadera tierra del desterrado, es lo inmenso, vacío pero surcable, es el espacio de la ruptura y de la unión entre dos orillas, de la separación en el viaje hacia el exilio pero también del posible camino del retorno a un origen, geográfico o simbólico, quizás, a veces pueda ocupar el espacio de un "ahí", inexistente en la poesía del exilio, entre un "aquí" impuesto y un "allî" inalcanzable (Sicot, 2006: 900).

El cuestionamiento central de la segunda generación es si ellos, al haber dejado España desde muy chicos, son transterrados; cómo vivieron el exilio y de qué manera éste impactó en su formación. El hecho es que, como dan cuenta ellos mismos, ${ }^{5}$ se les inculcó la idea de ser españoles y de que regresarían a su país de origen. Pero esto no ocurre en todos los casos y tenemos que, de ser una "generación", 6 hay muchos matices y diferencias entre los autores. Desde Tomás Segovia, Ramón Xirau, Manuel Durán hasta Gerardo Deniz, Federico Patán, entre otros, cada uno tiene una forma particular de asimilar su condición de "exilio" y la llevan a su literatura también de forma muy distinta. Lo que apunta Sicot es que hay un notable influjo de la tradición poética española y de la temática marítima, que bien puede presentarse como un territorio

${ }^{5}$ Aquí remitimos a las entrevistas a los escritores de esta segunda generación realizadas por Mateo Gambarte, incluidas en Literatura de los "niños de la guerra" del exilio español en México.

${ }^{6}$ Sin ahondar en el concepto de generación, retomamos de manera general la idea propuesta por Ortega y Gasset, entendiendo por tal el conjunto de escritores, poetas e intelectuales que comparten una visión de su entorno, ideológicamente hablando, dado que los autores de esta segunda generación comparten la filiación republicana de sus padres, entre otros aspectos. 
donde mar-tierra-cielo representan este espacio que marca la memoria.

Los poetas de la segunda generación del exilio republicano, especialmente los hispanomexicanos, tuvieron en Unamuno, en Juan Ramón Jiménez y en los exiliados de la Generación del 27 ilustres predecesores en el recurso del mar como compañero fiel o patria del exiliado. Pedro Salinas dedicó en el exilio, en 1946, con "El contemplado”, un poemario entero al mar (Sicot, 2004: 13).

El mar de los poetas, en particular las autoras que ahí abordamos, es el espacio mismo del exilio y de la memoria, presentado a partir de su mundo interior.

\section{Nueva generación: los hispanomexicanos}

Los estudios sobre el exilio en México se han centrado, según Mateo Gambarte, en el "exilio mayor" (1996: 10); es decir, los adultos republicanos que salieron al exilio y tuvieron como país receptor México. Se ha discutido ampliamente sobre la cuestión del exilio, particularmente el republicano, abordando la empresa cultural que significó y los profundos aportes a la cultura mexicana; en menor medida se ha trabajado con la "nueva generación", el "exilio menor", llamada la de los hispanomexicanos, aunque destacan algunos autores como Arturo Souto, Bernard Sicot, Eduardo Mateo Gambarte, Susana Rivera, Enrique López Aguilar, entre otros. "El primer problema que se plantea es el de si considerarlos o no como exiliados" (1996: 59). Y cita las palabras de uno de los integrantes de esta generación, Arturo Souto:

Los mayores "no pensaron tampoco en que estos niños abrieron sus conciencias a un mundo donde lo pasajero se había hecho artículo de fe, así como la frustración, el resentimiento y el reparto 
de culpabilidades. A la vez se mantuvo siempre la fe quijotesca en la vuelta y se detuvo el reloj en el 39. Fueron muchos, muchos los ańos en que esta juventud de la generación perdida no oyó hablar sino de los horrores de la guerra, las recriminaciones [...] (Mateo Gambarte, 1996: 61).

A través de entrevistas a diversas figuras de este "grupo" o "generación", Mateo Gambarte indaga y deja ver los acentuados matices de la conciencia de los hijos de refugiados respecto al exilio. Desde los autores que han seguido con este tema y se lo han apropiado como parte de su identidad hasta los autores que más bien consideran toda esa experiencia como algo ajeno y distante, y se consideran plenamente mexicanos. Independientemente de eso, sin pretender querer ver el acontecimiento y las circunstancias como aspectos tajantes en la formación de la identidad literaria de estos autores, tenemos que efectivamente en muchos de ellos se halla este tema muy presente, como es el caso de Arturo Souto y Angelina Muñiz-Huberman, por poner ejemplos. Al final, lo que destaca Mateo Gambarte como una de sus principales tesis es el conflicto de la identidad en muchos de los integrantes de este grupo: "el hijo del exiliado responde con angustia que es lo mismo que decir con inseguridad. Con ello la creación de la propia identidad es un problema de primer orden, a la vez que de una dificultad extrema" (1996: 102).

Perteneciente a esta segunda generación del exilio republicano en México, Arturo Souto retoma la idea de una "nueva generación", planteada por Aub, para dar el nombre de "hispanomexicanos" a este conjunto de autores nacidos entre 1924 y 1937: "Esta generación hispanomexicana, que se sitúa en el más amplio contexto de la poesía de los ańos cincuenta, posee suficientes rasgos comunes para ser considerada en su conjunto" (2008: 330). Esta categoría ha sido retomada por otros estudiosos del exilio espańol republica- 
no en México, como Angelina Muñiz-Huberman, Bernardo Sicot, Eduardo Mateo Gambarte, José María Espinasa, entre otros.

La identidad, como discurso de afirmación de los sujetos a cierta pertenencia, se vincula con diversos aspectos que van desde el territorio y los sucesos históricos (reconstruidos por la imaginación y la memoria) hasta la lengua, las costumbres y las tradiciones. En la literatura, particularmente en la poesía, la construcción de la identidad es también un factor de primer orden. El sujeto lírico, en este caso, se construye hasta cierta medida no como un sujeto homogéneo y unívoco, sino como un sujeto complejo, heterogéneo, plurívoco que se muestra a través del texto poético y se deja abierto a la interpretación.

En este sentido, en la generación de los hispanomexicanos, se manifiestan estas identidades literarias y poéticas, pues es un caso paradigmático de cómo los autores, poetas, parten de una concepción de sí mismos construida en gran medida por los relatos que asimilaron desde niños o jóvenes de formas muy diversas. Por poner un ejemplo de esto, citamos a Mateo Gambarte, donde recoge una anécdota de Angelina Muñiz y que nos muestra esta compleja formación de la identidad:

Angelina Muñiz me decía: creo que tienes razón al afirmar que el cuestionamiento de la identidad mexicana nos pudo asentar lo español. Cuando yo estaba en la escuela (mexicana), los niños mexicanos me atacaban como española, pero yo por dentro estaba tranquila porque yo veía que cuando querían apoyarse en algo decían: lo español. Pues yo llevo ventaja, pensaba yo, pues yo soy española sin duda. En ese momento frente a ellos yo sí me sentía definida (Mateo Gambarte, 1996: 104).

El hecho de enunciar el concepto "hispanomexicano", por parte de algunos de sus integrantes (como es el caso de Souto y Muñiz-Huberman), así como por estudiosos del tema, es en sí una 
muestra de esta búsqueda de identidad en un contexto adverso pues, como se ha dicho, a estos escritores no se les consideraba en España y ni en México. De haber crecido en un ambiente de alguna forma cerrado, cobran conciencia, como grupo, en la facultad de Filosofía y Letras -para los que ahí estudiaron-, ya que ahí es donde se establecen los vínculos que perduraron por años. Se proponen proyectos editoriales como las revistas, como Segrel, Clavileño y Presencia. Quienes participan en estos encuentros (en los espacios de la facultad y en las revistas) son el propio Arturo Souto, Manuel Durán, Tomás Segovia, Ramón Xirau, Luis Rius, además de Federico Patán, Angelina Muñiz-Huberman, José de la Colina, Francisca Perujo (quien después ocupará el cargo de la Dirección General de Publicaciones de la UNAM). Souto delimita muy bien la temporalidad de este grupo en cuanto a sus producciones:

En 1946 apareció el primer libro de esta generación: Puente, de Manuel Durán. Aparecerían después las revistas y en pocos años nuevos libros de poesía. Primeros poemas de Enrique de Rivas en 1949, La luz provisional de Tomás Segovia en 1950, Canciones de vela de Luis Rius en 1951, Con una mano en el ancla, de César Rodríguez Chicharro, en 1952. En 1954, Tiempo de Soledad, de José Pascual. En catalán, Ramón Xirau publicaría desde 1951. Años más tarde, García Ascot, Patán y Deniz. Y todavía inédita, en forma de libro, la poesía de Carlos Blanco, Francisca Perujo y Angelina Muñiz (Souto, 2008: 335).

Los estudiosos de esta generación coinciden en que se le ha prestado poca atención a estos autores en relación con su pertenencia generacional o de grupo. En efecto, si poco se ha analizado a Gerardo Deniz, a Ramón Xirau o a Federico Patán en su vinculación con el exilio y la manera en que éste es tratado como tema dentro de su obra, más desatendidas aún están las voces femeninas de esta generación. Como hemos visto, dentro del "canon" de los 
trece poetas hispanomexicanos (Sicot), se incluye a Parés, Perujo y Huberman, pero no se hace mención, por ejemplo, de otras poetas con una producción significativa como es el caso de Tere Medina (incluida en el Diccionario del exilio español en México, de Mateo Gambarte); también está la obra de poetas poco estudiadas como Carmen Castellote, Adriana Merino y Aurora Correa. ${ }^{7}$ Podemos afirmar que hay un grupo de poetas hispanomexicanos que se formó en la Universidad y que publicó sus primeras obras en torno a la década del 50. Las mujeres poetas aquí abordadas no pertenecieron enteramente a este grupo, pues no publicaron en estos ańos su obra, ni participaron en las revistas de ellos (como son Clavileño, Presencia, Segrel, Hoja). Sólo Nuria Parés publicó en los años cincuenta (Romances de la voz sola, en 1951, y Canto llano, en 1959), pero lo hizo al margen de este grupo, además de que ella no estuvo en la Universidad; Perujo y Muñiz publicaron su primeras obras poéticas en la década de los ochenta (Vilano al viento, de Muñiz, apareció en 1982 y Manuscrito de Milán, de Perujo, en 1985). Aunque no estuvieran involucradas directamente en los proyectos intelectuales de poetas como Tomás Segovia o Ramón Xirau, estas poetas sí son consideradas, en la reciente crítica, como parte de esta generación literaria a raíz de la antología de Peña Labra, que elaboraron Francisco Giner de los Ríos y la misma Francisca Perujo, así como los estudios de Bernardo Sicot y Eduardo Mateo

${ }^{7}$ Llegada a México como parte de los "niños de Morelia”, Aurora Correa publicó principalmente narrativa; de poesía sólo tiene una obra Odas (1976). Tere Medina, por su cuenta, publicó los libros de poesía El largo viaje (1972) y Rimas eróticas (1974). Adriana Merino publicó los poemarios: Crisol de lejana memoria (1974), Cósmica conciencia. Antología poética (1979) y Mi orfandad frente al mar (1982). Refugiada de niña en Rusia, Carmen Castellote llegó a México años después y publicó los libros de poesía Con suavidad de frío (1976), Vuelo de nieve a sol (1979), Diálogo con la esfinge (1983) y Acta de renacimiento (1985). 
Gambarte. Aun así, falta mucho por indagar en la producción de estas autoras que, aunque ya incluidas en esta segunda generación del exilio, siguen siendo menos atendidas.

\section{Voces femeninas de la generación hispanomexicana}

Nuria Parés nació en Barcelona en 1925 y llegó a México en 1942, lo que le da mayor conciencia de la guerra y el exilio. A diferencia de Perujo y Muñiz, ella no formó parte del círculo universitario donde se reunían algunos poetas y autores de esta generación, por lo que se mantuvo al margen de las dinámicas y publicaciones de este grupo. Sin embargo, tuvo el apoyo de algunos editores y autores importantes de la época, como León Felipe. Además publicó en revistas como Rueca, Diorama de la Cultura, Revista Mexicana de Cultura, entre otras. En 1951, aparece su primer libro, Romances de la voz sola; en 1959, su libro Canto llano, publicado en la colección Tenzontle del Fondo de Cultura Económica y su poemario Acapulco, y en 1987 su obra poética Colofón de luz, dedicada a Vicente Aleixandre, la cual ha sido interpretada como el colofón de la generación del 27, la cual influyó mucho en su escritura.

En su obra, Canto llano, encontramos una plena conciencia de la guerra, del exilio, y una memoria que expresa poéticamente los acontecimientos vividos. Así sucede en el poema "Sed" que dice: "¿Pedir? ¿Y a quién? ¿Y qué pedimos? / Sé que hubo un tiempo para pedir y para llorar, / el tiempo de la sal y de las lágrimas, / y hubo quien pidió pan / y quien pidió la paz y la palabra" (Parés, 1959: 16). De este modo, interpela el famoso poema de Blas de Otero, Pido la paz y la palabra, para hablar de esos momentos en que la poesía se volcó a tratar los acontecimientos de su época y su espacio: la trágica guerra, la derrota y persecución de los republicanos. A poco más de 20 años, en México, su memoria insiste con un tono que aún muestra un dolor al hablar del llanto, las lágrimas. 
Más adelante, en el mismo poema, dice: “Sed a los hombres de buena voluntad! / mandaron y el destino del hombre se hizo brasa, / candente mar por donde van los sueños / dando bandazos como viejas barcas" (Parés, 1959: 17). Vuelve así a la imagen de la sed, que titula el poema, y que no es más que la necesidad de beber, de agua, de vida. El tema del agua, de lo marítimo, se hace presente: el mar se enciende, y ahí van los sueńos, como barcas. Esto es una marca de la literatura del exilio espańol, según Sicot; por eso, con ello, Parés se incorpora a esta tradición. El exilio se presenta en este poema como una ausencia de vida, de agua, es la sed; a su vez hay un marcado pesimismo, un vacío que queda de esta conciencia del destierro: "Si es tiempo de sequía, tiempo acedo, / si a nuestro alrededor no queda nada, / ni se acabó la sal / y se ha acabado el llanto, la paz y la palabra. / ¿Qué podemos pedir? ¿Y a quién pedimos? I ¡Sólo queda la sed!... ¡La sed sin agua!" (Parés, 1959: 17).

La identidad poética queda manifiesta en este poemario, que, al quedar en esta-situación de desamparo, recurre a hablar de un nosotros. En su poema "Dicen..." leemos: "Que soy, que somos (nos lo dicen) / 'la España peregrina'... / ¡Ay, qué bonito nombre! / ¿Qué nombre tan bonito / para ir por el mundo a la deriva / como un barco de velas desplegadas, / como una extrańa carabela antigua!" (Parés, 1959: 21). Con cierta ironía se refiere a esa España peregrina, que no es otra que la Espańa de los transterrados que no olvidaron su condición e insistieron en su identidad; de esa España de la que ella sabe forma parte. El barco, la carabela antigua, son símbolos de este exilio y la tradición hispánica, como lo es el andar por el mundo a la deriva.

Francisca Perujo nació en Santander en 1934, sin embargo llegó a México de nińa, en 1939. Estudió en uno de los colegios que los exiliados republicanos fundaron para preservar la educación espańola en sus hijos, el Instituto Luis Vives, donde conoció a otros de los escritores hispanomexicanos como Gerardo Deniz (Juan Alme- 
la), César Rodríguez Chicharro y Enrique de Rivas. A diferencia de Parés, ella sí se involucró en la vida académica que aglutinaría en cierta medida a este grupo; se doctoró en Letras en la Facultad de Filosofía y Letras de la UNAM y trabajó para la Dirección General de Publicaciones de esta misma institución. Manuscrito en Milán (1985) es el título de su obra poética publicada. Algunos de sus poemas fueron incluidos en la antología de Bernardo Sicot Ecos del exilio: 13 poetas hispanomexicanos, así como en la antología de Peña Labra, que ella coordinó junto a Giner de los Ríos.

En el poema Herencia compartida, Perujo toma cierto reproche hacia la generación anterior, pues se nace o se impone desde niño la condición de peregrino y con ello surge una identidad quebrantada, aunque al fin sea una identidad. La memoria, como tema que toca en otros poemas de Manuscrito en Milán, es la que da la pauta para la constitución de la identidad que se expresa poéticamente:

Me decían que había nacido en una ciudad lejana, / más allá del océano, / pero ¿cómo era el muelle del que hablaban / las calles, cada casa? [...] Los otros venían de tierra adentro. / Ellos los conocían. / Muchos prefirieron el mar sin barcos. / ¿Olvidar? / ¿Qué? (Perujo, 1985: 29-30).

En general, los poemas hasta aquí vistos poseen un lenguaje muy directo, despojado de complejas metáforas, acorde a la poética mexicana de medio siglo, pero también a la intención particular del grupo por transmitir esta "angustia" por la identidad de la que habla Mateo Gambarte. En el caso de Perujo, en este poema, es notorio cómo se manifiesta cierta recriminación (que en el fondo no es tal) a los padres por la imposición de un pasado, de una memoria que luego será asimilada. El mar de los desterrados es aquí un "océano", lo cual resulta muy significativo pensando en el replanteamiento que aquí se hace; la ciudad lejana es eso, lejana y ajena en tanto no se conoce. Las preguntas en los versos, además de 
expresar ironía, manifiestan la verdadera duda de lo desconocido. ¿Cómo eran los muelles? ¿Cómo olvidar lo que nunca se ha vivido o, más bien, lo que nunca se ha retenido en la memoria? La voz de Perujo es muy fuerte y bien puede representar cierta actitud de muchos de los hispanomexicanos que aunque dialogan con su pasado hispánico también se replantean su adhesión a él.

Como consecuencia de la Guerra Civil, Angelina Muñiz nació en el exilio, en Hyères, Francia, en 1936. En 1942, su familia se establece en México, después de un lapso en Cuba. Como otros escritores de esta segunda generación hizo estudios en la UNAM, así como en otras instituciones del extranjero. La producción literaria de Muñiz es muy amplia, particularmente la poética, ${ }^{8}$ aunque es más conocida por su obra narrativa y ensayística. Ha obtenido importantes galardones como el Premio Xavier Villaurrutia (1985) y el Premio Sor Juana Inés de la Cruz (1993). Los temas recurrentes en su poesía son el erotismo, la pertenencia (y no-pertenencia), la persistencia, el camino-caminante, el exilio mítico, el mar, la identidad (presentada en su poesía como algo heterogéneo), entre otros. De las poetas abordadas en este artículo, e incluso dentro de la generación de hispanomexicanos, Muñiz-Huberman destaca por haber hecho del exilio el centro de su poética y su producción intelectual. Desde su primer libro, Vilano al viento: poemas del amor y del exilio (1982), se aprecia esta insistencia en la imagen del mar que, como hemos visto, estuvo tan presente en los exiliados republicanos. Angelina Muñiz, como otros poetas de su generación recomponen esa imagen del mar. No es ya el territorio donde comienza y termina el exilio, sino la representación de esa falta de pertenencia a un lugar en específico ("pasajero leve", "ligero de equipaje, / como buen marinero"). El mar se recompone desde esta mirada femenina, perteneciente a una nueva generación donde el

${ }^{8}$ En 2012, se publicó su poesía reunida bajo el título Rompeolas por el Fondo de Cultura Económica. 
exilio es un asunto de primer orden. Así, en su poema "La vida marinera I", nos encontramos con este abordaje directo a este tema:

Barcos, olas, espuma y peces. / Nítido cielo azul / sin una nube. / Viento suave / que riza la superficie. / Quisiera estar / a bordo de esa nave / hacia quién sabe / qué lugar. / Junto a los marineros, / uno más, / junto a los pescadores / uno más. / Te agobia / la montańa / y la tierra continua, / el techo sólido / el piso blando. / Por eso / le ríes al mar / y te embarcas, / pasajero leve, / sin volver la cabeza atrás. / Ligero de equipaje, / como buen marinero, / sólo firme / en la tabla vacilante, / cuando todo el / horizonte / es mar-cielo, / cuando sólo queda / agua y más agua por camino (Muñiz, 1982: 15).

El mar ya no representa el momento trágico de la partida, de la derrota. No es solamente el origen del exilio. Con más de 40 años de por medio, la poeta retoma este motivo de la tradición literaria que viene desde la épica griega: el mar, particularmente de la generación que la precedió. Aquí el mar se halla asimilado a una forma de "vida", es la vida marinera, y lo que predomina no es la angustia y la tristeza, tampoco la nostalgia. Desde el primer verso se dibuja una escena plácida, de tranquilidad e incluso felicidad. Enseguida, usando una "segunda persona", dice: "Quisieras estar / a bordo de esa nave / hacia quién sabe / qué lugar”. Así le habla a su otro yo, dejado en el pasado, pero habiendo asimilado la experiencia vivida. La partida, el exilio, pierde los rasgos terribles pues aquí la voz poética está feliz, entusiasmada por el destino incierto, por la falta de anclas. Con la tercera estrofa se reafirma esto, al contraponer el suelo firme, el arraigo, y el mar, que entonces representa esta apertura al constante cambio, a la mudanza interna. Y como Muñiz dirá en sus ensayos, el exiliado suele ser un viajero, un pasajero de "ligero equipaje", pues todo lo que posee lo pierde sin darse cuenta que en esa pérdida hay todo un porvenir por construir. Esta mi- 
rada optimista, que si bien tiene sus matices, sólo es posible con todo este tiempo de por medio. Pero la memoria insiste en el tema de este mar omnipresente que en el horizonte se funde con el cielo.

Tenemos entonces, por una parte, esta visión optimista del desarraigo, pero, por otra, también se encuentra el dolor por la guerra y sus pérdidas -cuestión de la que habla Souto y que retomamos en el epígrafe de este artículo-. En la parte que habla del exilio, está el poema "El largo camino": "Lanzar un grito / aquí / y allá. / Un dolor que duele / El campesino muerto / El guerrero olvidado / El amor que no llega. / El exilio / Siempre el exilio / En el centro / el exilio" (Muñiz, 1982: 27). En la parte que alude al "largo camino" se puede apreciar que es la vida de un ser errante que ha sido despojado de su espacio, lo que conduce a ese "dolor que duele". El yo lírico revive aquí un tanto de sus recuerdos, pero sobre todo de lo que supo con el tiempo, en gran parte por las historias de sus padres. Hay un "aquî" y un "allá"; el aqui como un lugar indeterminado desde el cual se reconstruye el otro lugar, perdido, donde acontecieron los hechos, donde se encontraba el "campesino muerto". El generador de la historia es siempre el exilio, desde los tiempos míticos hasta el exilio es el centro. Es por ello que retoma también la violencia inherente a esta expulsión: "Los cadáveres desparramados / No hay sangre en los niños / Caen las gotas, / gotas por todas partes. / Son demasiadas / y no hay quien las recoja / (Gotas de sangre que se escapa)" (27).

Es ese entorno violento descrito poéticamente, que la voz lírica le habla al "caminante", otro de los motivos de la poesía del exilio. Es un caminante no-nato, que pese a ello "hereda" la condición del exiliado. Es el peregrino que desde antes de nacer ya lo es y sólo en su "oficio de caminante", en su propio "peregrinar" hará conciencia de esto para así forjar su propia identidad, individual y colectiva: "Tu oficio es caminante / ¿Lo recuerdas? / Ya tu madre caminaba / contigo adentro / Embrión fatigado antes de nacer / 
Embrión de lágrimas convulsas, / de espasmos reprimidos, / de espacio cerrado, / prisionero sin cárcel, / sin aire, / sin voz. / Inútil rebelarse, / confinado sin paisaje, / ¿qué sería el cielo y la tierra?” (27-28).

Es con estos versos que puede plantearse un matiz temático propuesto por este grupo en específico; aquí se presenta al exiliado, no sólo niño o adolescente que carga con las decisiones de los adultos, sino que es llevado al extremo: es el embrión. Parte de su propia "vivencia", pues ella comenzó el exilio en el vientre de su madre, lo cual se convirtió en otro de los elementos de su poética. En ese espacio confinado que es la matriz, sin ver ningún paisaje, sin posibilidad de rebelarse, el "embrión" es un exiliado incluso antes de nacer. Su oficio queda marcado: es el peregrino, el caminante. Pero no solamente se ve aquí reflejado el punto de vista de un hijo de exiliado, sino sobre todo la voz "femenina" en el tema de la maternidad, de la madre, y la imagen de la matriz como el espacio cerrado y seguro.

Si bien el exilio español en México aún tiene mucho qué decir, en cuanto a las relaciones que estableció con la cultura mexicana, la literatura de la última generación del exilio ha recobrado un interés por parte de los estudios literarios y culturales. Muchas son las ramas que pueden abordarse en este sentido. La reedición de las revistas producidas en ese momento es un síntoma de este reavivado interés en esta generación, aunque aún falta por hacer. Hay muchos aspectos que puntualizar, debates que también han quedado en el tintero y hasta hace pocos años se han retomado. En este contexto, seguir la rama de las escritoras y poetas hispanomexicanas deberá llevar primero a un rescate necesario de su obra, prácticamente desconocida en algunos casos o bien dejada al margen por la crítica. Anclado a la modernidad, el exilio se revisa hoy desde uno de sus propios pilares: la identidad. Y el hecho de postular una identidad literaria es una forma de afirmar la huma- 
nidad que hay detrás de estas escrituras, de situarlas en el tiempo y el espacio, en su propia mundanidad. Esto nos posibilita a acercarnos a la poética de estas autoras, a su particular reconstrucción del exilio; pues la identidad, femenina y del exilio, en su caso, no nos lleva, afortunadamente, a una representación unívoca del sujeto, sino que trae consigo sus propias contradicciones, complejidades y replanteamientos.

\section{Bibliografía}

Aub, Max, 1987, "Una nueva generación”, en Sala de espera, México, Pangea.

Aznar Soler, Manuel, 2006, Escritores, editoriales y revistas del exilio republicano de 1939, Sevilla, Editorial Renacimiento Universitat Autònoma de Barcelona-Grupo de Estudios del Exilio Literario.

Corral, Rose, 1995, Poesía y exilio: los poetas del exilio español en México, México, Colmex.

Espinasa, José María, 2014, Presencia, México, Ediciones sin Nombre/Ateneo de España.

Gaos, José, 1994, "Confesiones del transterrado", Universidad de México, núm. 521, México, junio, pp. 3-9.

Giner de los Ríos, Francisco y Francisca Perujo, 1980, Segunda generación de poetas españoles del exilio mexicano, Santaner, Peña Labra.

Guillén, Claudio, 1995, El sol de los desterrados: literatura y exilio, Barcelona, Quaderns Crema.

Mateo Gambarte, Eduardo, 1996, Literatura de los "niños de la guerra" del exilio español en México, Lleida, Pagès Editors Universitat de Lleida. 
, 1997, Diccionario del exilio español en México: de Carlos Blanco Aguinaga a Ramón Xirau, Pamplona, Eunate.

Muñiz-Huberman, Angelina, 1982, Vilano al viento. Poemas del amor y del exilio, México, UNAM.

, 1999, El canto peregrino: hacia una poética del exilio, Barcelona/México, Cop d'Idees-Gexel/UNAM.

Parés, Nuria, 1959, Canto llano, México, FCE.

Perujo, Francisca, 1985, Manuscrito en Milán, Valencia, Pre-textos.

Ricoeur, Paul, 1995, Tiempo y narración, México, Siglo XXI.

Rivera, Susana, 1990, Última voz del exilio: el grupo poético hispano-mexicano, Madrid, Hiperión.

Segovia, Tomás, 2007, Sobre exiliados, México, Colmex.

Sicot, Bernardo, 2003, Ecos del exilio: 13 poetas hispanomexicanos, A Coruña, Edicios do Castro.

, 2004, "El mar de los desterrados. Desde Unamuno hasta los poetas hispanoamericanos", Revista de la Universidad de México, núm. 10, diciembre, pp. 5-23.

, 2006, "La poesía de Angelina Muñiz-Huberman: faro seguro, lugares inciertos", en Escritores, editoriales y revistas del exilio republicano de 1939, Manuel Aznar Soler (ed.), Sevilla, Editorial Renacimiento Universitat Autònoma de Barcelona/ Grupo de Estudios del Exilio Literario, pp. 895-905.

Souto Alabarce, Arturo, 2008, "Sobre una generación de poetas hispanomexicanos", Revista Diálogos: antología, José María Espinasa (comp.), México, Colmex, pp. 330-337.

Zambrano, María, 1993, Filosofía y poesía, México, FCE. 